\title{
PENGARUH PROMOSI DAN FASILITAS TERHADAP JUMLAH PENGUNJUNG PADA MUSEUM DAERAH KABUPATEN DELI SERDANG
}

\author{
Rismayanti Simatupang, Husni Mubarak, M.Abbas \\ Alumni Sekolah Tinggi Ilmu Manajemen Sukma \\ Program studi Manajemen, Sekolah Tinggi Ilmu Manajemen \\ husnimubarak0707@gmail.com abbashmad990@gmail.com
}

\begin{abstract}
The objective of this research is to find out the effect of promotion and facility to the number of visitors at Deli Serdang regency museum, sample collection uses saturated sampling technique which means that sample determining if all members of population is used as sample. The data analysis uses multiple linear regression test with modal constancy (classical assumption test), hypothesis test uses determination coefficient test $\left(R^{2}\right)$, simultaneous test $\left(F_{\text {test }}\right)$ and partial test $\left(t_{\text {test }}\right)$, whereas data processing uses SPSS program. The research result shows that determination coefficient test $\left(R^{2}\right)$ Promotion and Facility variable can explain variation that happen to the Number of Visitors variable, in addition simultaneously shows that Promotion and Facility variable affect positively and significantly to the Number of Visitors, whereas promotion variable partially affect to the Number of Visitors variable while facility variable partially affect to Number of Visitors.

Keyword: Promotion, Facility, and Number of Visitors
\end{abstract}

\section{PENDAHULUAN}

Suatu kegiatan promosi jika dilaksanakan dengan baik dapat mempengaruhi konsumen mengenai dimana dan bagaimana konsumen membelanjakan pendapatannya. Biasanya berbagai macam promosi yang dilakukan untuk memperkenalkan suatu produk dari sebuah perusahaan yang dimana bertujuan untuk memberikan informasi, menarik perhatian dan selanjutnya memberi pengaruh untuk meningkatkan penjualan. Periklanan merupakan unsur promosi yang paling banyak dan paling sering dilakukan sehingga menarik minat pengunjung untuk datang berkunjung. Disamping kelengkapan cara mempromosikan suatu produk kita juga harus memperhatikan kelengkapan fasilitas yang mendukung sehingga pengunjung merasa nyaman, aman dan tertarik untuk datang kembali. Kemudian disimpulkan bahwa promosi dan ketersediaan fasilitas sangatlah mempengaruhi kenyamanan dan minat berkunjung wisatawan.

Penelitian yang dilakukan Novena (2013:31) dalam jurnalnya yang berjudul "pengaruh bauran promosi terhadap keputusan kunjungan konsumen pariwisata" mengatakan bahwa tujuan utama promosi adalah menginformasikan, mempengaruhi dan membujuk serta mengingatkan konsumen sasaran tentang perusahaan dan bauran pemasaran. Menurut Marvidola (2014:8) dalam jurnalnya yang berjudul "presepsi wisatawan tentang promosi dan fasilitas objek wisata museum adityawarman di kota padang" mengatakan bahwa fasilitas adalah pelayanan pendukung yang selalu siap dimanfaatkan oleh para pegunjung dan pelayanan tersebut menawarkan mutu dan harga yang sesuai dengan kebutuhan wisatawan. Promosi ditinjau dari indikator Advertising (periklanan) dan fasilitas ditinjau dari indikator bentuk fasilitas, fungsi fasilitas. Secara umum bentuk promosi memiliki fungsi yang sama, tetapi bentuk tersebut dapat dibedakan berdasarkan tugas-tugas khususnya, beberapa tugas khusus tersebut sering disebut bauran promosi yang salah satunya adalah promosi penjualan. 


\section{Perumusan Masalah}

Berdasarkan uraian diatas maka penulis merumuskan masalah sebagai berikut:

1. Apakah ada pengaruh promosi terhadap jumlah penggunjung pada museum daerah kabupaten deli serdang?"

2. Apakah ada pengaruh fasilitas terhadap jumlah penggunjung pada museum daerah kabupaten deli serdang?"

3. Apakah ada pengaruh promosi dan fasilitas terhadap jumlah penggunjung pada museum daerah kabupaten deli serdang?"

\section{Batasan Masalah}

Dengan keterbatasan penulis baik waktu dan pengetahuan maka penelitian ini dibatasi pada penggunjung Museum Daerah kabupaten Deli Serdang pada tanggal 28-29 Mei 2017.

\section{Tujuan Penelitian}

Adapun tujuan penelitian ini antara lain:

1. Untuk mengetahui pengaruh promosi terhadap jumlah penggunjung pada museum daerah kabupaten deli serdang.

2. Untuk mengetahui pengaruh fasilitas terhadap jumlah penggunjung pada museum daerah kabupaten deli serdang.

3. Untuk mengetahui pengaruh promosi dan fasilitas terhadap jumlah penggunjung pada museum daerah kabupaten deli serdang.

\section{METODE PENELITIAN}

\section{Tempat dan Waktu Penelitian}

Penelitian ini dilakukan di Museum Daerah Kabupaten Deli Serdang, Kompleks Perkantoran Pemkab Deli Serdang yang dilaksanakan pada bulan Maret sampai Juni 2017.

\section{Jenis dan Sumber Data}

\section{Jenis Data}

Data yang digunakan dalam penelitian ini adalah data primer dan data sekunder.

1. Data primer adalah data yang langsung diberikan kepada pengumpul data atau yang dalam hal ini peneliti memperoleh data primer dengan cara menyebar kuisioner kepada Pengunjung Museum Daerah Kabupaten Deli Serdang.

2. Data sekunder adalah data yang diperoleh oleh pengumpul data tidak secara langsung dari sumber data, adapun yang menjadi data sekunder dalam penelitian ini yaitu dengan mengumpulkan teori-teori dan informasi yang besumber dari kajian kepustakaan berupa buku-buku referensi baik milik sendiri maupun dari perpustakaan, berbagai catatan-catatan yang diperoleh dari perusahaan, dan penelitian-penelitian terdahulu terkait dengan variabel-variabel yang menjadi permasalahan yang diteliti.

\section{Sumber Data}

Sumber data yang digunakan yaitu:

1. Data Internal yaitu data yang diperoleh dari dalam pihak Museum Daerah Kabupaten Deli Serdang.

2. Data Eksternal adalah data yang didapat dari luar tempat penelitian seperti internet dan perpustakaan. 


\section{Metode Pengumpulan Data}

Metode pengumpulan data yang digunakan dalam penelitian ini sebagai berikut:

1. Studi Dokumentasi: pengumpulan data yang dilakukan dengan mencari informasi berdasarkan dokumen-dokumen perusahaan yang berkaitan dengan penelitian.

2. Kuesioner: metode pengumpulan data dengan membuat daftar pernyataan dalam bentuk angket yang ditujukan kepada responden yang dijadikan sampel.

3. Observasi: pengamatan data melalui pengamatan secara langsung di museum daerah kabupaten deli serdang.

\section{Defenisi Operasional}

Berdasarkan rumusan masalah, maka variabel-variabel dalam penelitian ini dapat diidentifikasi sebagai berikut:

1. Variabel bebas ( Variabel Independen ) adalah variabel yang mempengaruhi variabel terkait, yang terdiri dari Promosi $\left(\mathrm{X}_{1}\right)$ dan Fasilitas $\left(\mathrm{X}_{2}\right)$.

2. Variabel Terikat (Variabel Dependen) adalah Variabel yang dipengaruhi oleh variabel bebas, yaitu jumlah pengunjung $(\mathrm{Y})$.

Tabel 1. Operasionalisasi Variabel Penelitian

\begin{tabular}{|c|c|c|c|}
\hline Variabel & Defenisi & Indikator & $\begin{array}{l}\text { Sk } \\
\text { ala } \\
\text { Ukur }\end{array}$ \\
\hline $\begin{array}{l}\text { Promosi } \\
\left(\mathrm{X}_{1}\right)\end{array}$ & $\begin{array}{l}\text { promosi merupakan } \\
\text { kegiatan yang ditujukan } \\
\text { untuk mempengaruhi } \\
\text { customer agar mereka } \\
\text { menjadi kenal dengan } \\
\text { produk oleh organisasi } \\
\text { kepada mereka. }\end{array}$ & $\begin{array}{ll}\text { 1. } & \text { Advertising } \\
\text { 2. } & \text { Sales promotion, } \\
\text { 3. } & \text { Public Relation, } \\
\text { 4. } & \text { Personal Selling, }\end{array}$ & \multirow[t]{3}{*}{$\begin{array}{l}\mathrm{Li} \\
\text { kert }\end{array}$} \\
\hline $\begin{array}{l}\text { Fasilitas } \\
\left(\mathrm{X}_{2}\right)\end{array}$ & $\begin{array}{l}\text { Pelayanan } \\
\text { pendukung yang selalu } \\
\text { siap dimanfaatkan oleh } \\
\text { para wisatawan dan } \\
\text { pelayanan tersebut } \\
\text { menawarkan mutu dan } \\
\text { harga yang sesuai } \\
\text { dengan kebutuhan } \\
\text { wisatawan }\end{array}$ & $\begin{array}{l}\text { 1. Kondisi dan kelengkapan } \\
\text { fasilitas. } \\
\text { 2. Biaya dari fasilitas yang } \\
\text { digunakan. } \\
\text { 3. Aksesibilitas. } \\
\text { 4. Adekuasi / persediaan fasilitas } \\
\text { yang diperlukan. } \\
\text { 5. Topografi dan letak geografis }\end{array}$ & \\
\hline $\begin{array}{l}\text { Jumlah } \\
\text { pengunjung } \\
\text { (Y) }\end{array}$ & $\begin{array}{l}\text { Wisatawan adalah } \\
\text { orang yang mengadakan } \\
\text { perjalanan dari tempat } \\
\text { kediamannya tanpa } \\
\text { menetap di tempat yang } \\
\text { didatanginya atau hanya } \\
\text { untuk sementara waktu } \\
\text { tinggal di tempat yang } \\
\text { didatanginya. }\end{array}$ & $\begin{array}{ll}\text { 1. } & \text { Faktor Budaya } \\
\text { 2. } & \text { Faktor Sosial } \\
\text { 3. } & \text { Faktor Pribadi } \\
\text { 4. } & \text { Faktor Psikologis }\end{array}$ & \\
\hline
\end{tabular}

Sumber: Sudarmo dalam Zebua (2016:15), Kotler pada Manap (2016:304), Mill pada Marvidola (2014:10), Nuriata (2014:62), Soekadijo dalam Taufik (2016), Kotler dan Keller (2012:214). 


\section{Uji Validitas dan reliabilitas}

Menurut (Sugiyono,2016:348) "uji validitas adalah pengujian yang dilakukan terhadap isi suatu instrument, dengan tujuan untuk mengukur ketepatan insturmen yang digunakan dalam suatu penelitian". Dikatakan valid jika nilai $r_{\text {hitung }}>r_{\text {tabel }}$ dan dikatakan tidak valid jika nilai $r_{\text {hitung }}<r_{\text {tabel. }}$.

Menurut (Sugiyono,2016:348) "uji reliabilitas adalah proses pengukuran terhadap ketepatan (konsisten) dari suatu insturmen". Dikatakan reliable jika nilai crombach alfa $>0,6$ dan dikatakan tidak reliable jika nilai crombach alfa $<0,6$.

\section{Metode Analisis Data}

Metode analisis data yang digunakan dalam penelitian ini adalah metode deskriptif kuantitatif,sedangkan model analisis yang digunakan dalam penelitian ini adalah Regresi linear berganda, dengan model persamaan: $\quad \mathbf{Y}=\mathbf{a}+\mathbf{b} \mathbf{X}_{1}+\mathbf{b} \mathbf{X}_{2}+\mathbf{e}$ dimana:

$$
\begin{aligned}
& \mathrm{Y}=\text { Jumlah Pengunjung } \\
& \mathrm{X}_{1}=\text { Promosi } \\
& \mathrm{X}_{2}=\text { Fasilitas } \\
& \mathrm{b}_{1}=\text { koefisien regresi variabel promosi } \\
& \mathrm{b}_{2}=\text { koefisien regresi variabel fasilitas } \\
& \mathrm{e}=\text { Error of term (variabel yang tidak diteliti) }
\end{aligned}
$$

\section{Kerangka Berfikir}

Promosi adalah sejenis komunikasi yang memberi penjelasan yang meyakinkan calon konsumen tentang barang dan jasa. Fasilitas merupakan perlengkapan yang perlu disiapkan ditempat tujuan, menyertai kehadiran atraksi wisata. Pertumbuhan fasilitas wisata akan seiring dengan perkembangan atraksi wisata. Kehadiran Fasilitas wisata ditempat tujuan wisata melengkapi atarksi wisata yang mempunyai daya tarik kepada wisatawan. Wisatawan adalah semua orang yang memenuhi dua syarat, pertama mereka meninggalkan rumah kediamannya untuk jangka waktu kurang dari satu tahun dan kedua bahwa sementara mereka pergi, mereka mengeluarkan uang ditempat mereka kunjungi tidak mencari nafka ditempat tersebut.

\section{Hipotesis}

Menurut (Sugiyono,2016:84). Hipotesis diartikan sebagai jawaban sementara terhadap rumusan masalah penelitian. Rumusan masalah tersebut bisa berupa pernyataan tentang hubungan dua variabel atau lebih, perbandingan (komparasi), atau variabel mandiri (Deskripsi). Hipotesis dalam penelitian ini ada pengaruh promosi dan fasilitas terhadap jumlah pengunjung pada museum daerah kabupaten deli serdang secara parsial dan simultan.

\section{Pengujian Hipotesis}

1. Koefisien Determinasi $\left(\mathrm{R}^{2}\right)$

Koefisien Determinasi $\left(\mathrm{R}^{2}\right)$ untuk mengukur seberapa besar kemampuan model dalam menerangkan variable terikat. Semakin besar nilai koefisien (mendekati satu) maka dapat dikatakan bahwa ada pengaruh pada variable bebas $\left(\mathrm{X}_{1}\right)$ dan $\left(\mathrm{X}_{2}\right)$ terhadap variable $(\mathrm{Y})$.

\section{Uji Simultan (Uji F)}

Untuk menguji hipotesis penelitian ini digunakan uji simultan (uji F) untuk melihat pengaruh promosi dan fasilitas secara simultan terhadap jumlah pengunjung pada museum daerah kabupaten deli serdang. Pengujian dilakukan pada tingkat kepercayaan $90 \%$ atau tingkat kesalahan $\alpha=0.1(10 \%)$ dengan kriteria:

a. Jika $\mathrm{F}_{\text {hitung }}<\mathrm{F}_{\text {tabel}}$, maka $\mathrm{H}_{0}$ diterima, $\mathrm{H}_{1}$ ditolak, artinya secara simultan penelitian ini tidak pengaruh. 
b. Jika $\mathrm{F}_{\text {hitung }}>\mathrm{F}_{\text {tabel }}$, maka $\mathrm{H}_{0}$ ditolak, $\mathrm{H}_{1}$ diterima, artinya secara simultan penelitian ada pengaruh.

3. Uji Persial (uji t)

Uji persial (uji t) bertujuan untuk melihat pengaruh promosi dan fasilitas, secara persial terhadap jumlah pengunjung pada museum daerah kabupaten deli serdang, dengan kriteria:

a. Jika $t_{\text {hitung }}<t_{\text {tabel, }}$, maka $\mathrm{H}_{0}$ diterima, $\mathrm{H}_{1}$ ditolak, artinya secara persial penelitian ini tidak pengaruh.

b. Jika $t_{\text {hitung }}>t_{\text {tabel }}$, maka $\mathrm{H}_{0}$ ditolak, $\mathrm{H}_{1}$ diterima, artinya secara persial penelitian ada pengaruh.

\section{HASIL PENELITIAN DAN PEMBAHASAN}

\section{Hasil Penelitian}

\section{Uji Validitas dan Reliabilitas}

Uji validitas digunakan untuk melihat ketepatan instrumen yang digunakan dalam penelitian. Instrument dikatakan validitas jika nilai $r_{\text {hitung }}>r_{\text {tabel. }}$. Hasil validitas dari setiap instrumen variabel penelitian adalah sebagai berikut:

Tabel 2. Validitas Instrumen Variabel Promosi $\left(\mathrm{X}_{1}\right)$

\begin{tabular}{|l|l|l|l|}
\hline \multirow{2}{*}{ Instrumen } & \multicolumn{2}{|l|}{ Nilai Validitas } & \multirow{2}{*}{ Kesimpulan } \\
\cline { 2 - 2 } & rhitung & Rtabel & \\
\hline Promosi 1 & 0,466 & & Valid \\
\hline Promosi 2 & 0,726 & & Valid \\
\hline Promosi 3 & 0,643 & \multirow{4}{*}{0.228} & Valid \\
\hline Promosi 4 & 0,734 & Valid \\
\hline Promosi 5 & 0,718 & Valid \\
\hline Promosi 6 & 0,484 & Valid \\
\hline Promosi 7 & 0,604 & & Valid \\
\hline Promosi 8 & 0,669 & & Valid \\
\hline Promosi 9 & 0,611 & & Valid \\
\hline Promosi 10 & 0,469 & & Valid \\
\hline
\end{tabular}

Dari tabel 2. terlihat bahwa hasil pengujian masing-masing instrumen variabel Promosi $\left(\mathrm{X}_{1}\right)$ memiliki nilai $\mathrm{r}_{\text {hitung }}>0.228$, dengan demikian dapat disimpulkan bahwa secara keseluruhan instrumen pernyataan dari variabel Promosi yang digunakan valid.

Tabel 3. Validitas Instrumen Variabel Fasilitas $\left(\mathrm{X}_{2}\right)$

\begin{tabular}{|l|l|l|l|}
\hline \multirow{2}{*}{ Instrumen } & \multicolumn{2}{|l|}{ Nilai Validitas } & \multirow{2}{*}{ Kesimpulan } \\
\cline { 2 - 2 } & rhitung & Rtabel & \\
\hline Fasilitas 1 & 0,607 & & Valid \\
\hline Fasilitas 2 & 0,641 & \multirow{4}{*}{0.228} & Valid \\
\hline Fasilitas 3 & 0,720 & Valid \\
\hline Fasilitas 4 & 0,679 & Valid \\
\hline Fasilitas 5 & 0,737 & & Valid \\
\hline Fasilitas 6 & 0,788 & & Valid \\
\hline Fasilitas 7 & 0,794 & & Valid \\
\hline Fasilitas 8 & 0,754 & & Valid \\
\hline
\end{tabular}




\begin{tabular}{|l|l|l|l|} 
Fasilitas 9 & 0,778 & & Valid \\
\hline Fasilitas 10 & 0,818 & & Valid \\
\hline
\end{tabular}

Dari tabel 3. terlihat bahwa hasil pengujian masing-masing instrumen variabel Fasilitas $\left(\mathrm{X}_{2}\right)$ memiliki nilai $\mathrm{r}_{\text {hitung }}>0.228$, dengan demikian dapat disimpulkan bahwa secara keseluruhan instrumen pernyataan dari variabel Fasilitas yang digunakan valid.

Tabel 4. Validitas Instrumen Variabel Jumlah Pengunjung (Y)

\begin{tabular}{|l|l|l|l|}
\hline \multirow{2}{*}{ Instrumen } & \multicolumn{2}{|l|}{ Nilai Validitas } & \multirow{2}{*}{ Kesimpulan } \\
\cline { 2 - 2 } & rhitung & Rtabel & \\
\hline Jumlah Kunjungan 1 & 0,454 & & Valid \\
\hline Jumlah Kunjungan 2 & 0,733 & & Valid \\
\hline Jumlah Kunjungan 3 & 0,536 & Valid \\
\hline Jumlah Kunjungan 4 & 0,720 & & Valid \\
\hline Jumlah Kunjungan 5 & 0,702 & \multirow{4}{*}{0.228} & Valid \\
\hline Jumlah Kunjungan 6 & 0,697 & Valid \\
\hline Jumlah Kunjungan 7 & 0,637 & & Valid \\
\hline Jumlah Kunjungan 8 & 0,665 & & Valid \\
\hline Jumlah Kunjungan 9 & 0,622 & & Valid \\
\hline Jumlah Kunjungan 10 & 0,609 & & Valid \\
\hline
\end{tabular}

Dari tabel 4. terlihat bahwa hasil pengujian masing-masing instrumen variabel Jumlah pengunjung $(\mathrm{Y})$ memiliki nilai $\mathrm{r}_{\text {hitung }}>0.228$, dengan demikian dapat disimpulkan bahwa secara keseluruhan instrumen pernyataan dari variabel jumlah pengunjung yang digunakan valid.

Instrumen dikatakan reliabel jika nilai cronbach alfa hitung > cronbach alfa toleransi (0.6). hasil pengujian reliabilitas terlihat seperti berikut ini:

Tabel 5. Hasil Relibilitas Instrumen Penelitian

\begin{tabular}{|l|l|l|l|}
\hline No & Variabel & $\begin{array}{l}\text { Nilai Cronbach 's } \\
\text { Alfa }\end{array}$ & Kesimpulan \\
\hline 1 & Promosi $\left(\mathrm{X}_{1}\right)$ & 0.881 & Reliabel \\
\hline 2 & Fasilitas $\left(\mathrm{X}_{2}\right)$ & 0.930 & Reliabel \\
\hline 3 & Jumlah Pengunjung $(\mathrm{Y})$ & 0.887 & Reliabel \\
\hline
\end{tabular}

Hasil uji reliabilitas menunjukkan bahwa nilai Cronbach 's Alfa seluruh variabel lebih besar dari 0.6, maka dapat disimpulkan bahwa kuisioner penelitian ini dikatakan reliabel. 


\section{Hasil Uji Regresi Linear Berganda}

Pengujian ini dilakukan untuk mengetahui pengaruh promosi dan fasilitas terhadap jumlah pengunjung pada Museum Daerah Kabupaten Deli Serdang. Berikut ini tabel hasil pengujian regresi linear berganda pada masing-masing variabel yaitu:

Tabel 6. Hasil Uji Regresi Linear Berganda

\section{Coefficients}

\begin{tabular}{|l|l|l|l|l|l|}
\hline Model & \multicolumn{2}{|l|}{$\begin{array}{l}\text { Unstandardized } \\
\text { Coefficients }\end{array}$} & $\begin{array}{l}\text { Standardized } \\
\text { Coefficients }\end{array}$ & \multirow{2}{*}{ Sig. } \\
\cline { 2 - 4 } & $\mathrm{B}$ & Std. Error & Beta & & \\
\hline (Constant) & 8.512 & 3.503 & & 2.430 & .018 \\
X1 & .557 & .133 & .527 & 4.189 & .000 \\
X2 & .222 & .102 & .274 & 2.178 & .033 \\
\hline
\end{tabular}

a. Dependent Variable: Y

Berdasarkan hasil pengujian diatas, maka diperoleh persamaan regresi linear berganda sebagai berikut: $\mathrm{Y}=8.512+0.557+0.222$

Pada model regresi linear berganda diperoleh nilai konstanta jumlah pengunjung sebesar 8.512 artinya jika nilai variabel bebas $\left(\mathrm{X}_{1}\right.$ dan $\left.\mathrm{X}_{2}\right)$ nilainya 0 , maka variabel terikat $(\mathrm{Y})$ nilainya sebesar 8.512 . koefisien regresi masing-masing variabel bebas bernilai positif, artinya jumlah pengunjung pada Museum Daerah Kabupaten Deli Serdang dapat dipengaruhi oleh Promosi dan Fasilitas.

\section{Pengujian Hipotesis}

a. Koefisien Deteminasi $\left(\mathrm{R}^{2}\right)$

Koefisien determinasi bertujuan untuk mengukur berapa besar kemampuan variabel bebas dalam menerangkan variabel terikat. Nilai koefisien determinasi dapat dilihat pada tabel berikut:

Tabel 7. Hasil Uji Koefisien Determinasi $\left(\mathrm{R}^{2}\right)$

\section{Model Summary}

\begin{tabular}{|l|l|l|l|l|}
\hline Model & $\mathrm{R}$ & $\mathrm{R}$ Square & $\begin{array}{l}\text { Adjusted } \\
\text { Square }\end{array}$ & $\begin{array}{l}\mathrm{R} \\
\text { Std. Error of the } \\
\text { Estimate }\end{array}$ \\
\hline 1 & $.764^{\mathrm{a}}$ & .584 & .573 & 2.420 \\
\hline
\end{tabular}

a. Predictors: (Constant), X2, X1

Nilai koefisien determinasi yang diperoleh sebesar 0.584 atau $58.4 \%$ menunjukkan bahwa variabel promosi dan fasilitas dapat mempengaruhi jumlah pengunjung pada Museum Daerah Kabupaten Deli Serdang, sedangkan sisanya 41.6\% dipengaruhi oleh variabel lain yang tidak diteliti oleh peneliti dalam penelitian ini.

b. Uji Simultan (Uji F)

Uji simultan (uji F), uji ini dilakukan untuk melihat pengaruh promosi dan fasilitas secara simultan terhadap jumlah pengunjung pada Museum Daerah Kabupaten Deli Serdang , pengujian dilakukan pada tingkat kepercayaan 95\% atau tingkat kesalahan $\alpha=$ $0.05(5 \%)$, dengan kriteria:

a. Jika $\mathrm{F}_{\text {hitung }}<\mathrm{F}_{\text {tabel }}$, maka $\mathrm{H}_{0}$ diterima, $\mathrm{H}_{1}$ ditolak, artinya secara simultan penelitian ini tidak berpengaruh.

b. Jika $\mathrm{F}_{\text {hitung }}>\mathrm{F}_{\text {tabel}}$, maka $\mathrm{H}_{0}$ ditolak, $\mathrm{H}_{1}$ diterima, artinya secara simultan penelitian ini berpengaruh. 
Tabel 8. Hasil Uji Simultan (Uji F)

ANOVA $^{\mathrm{a}}$

\begin{tabular}{|c|c|c|c|c|c|c|}
\hline Model & & Sum of Squares & $\mathrm{df}$ & Mean Square & $\mathrm{F}$ & Sig. \\
\hline & Regression & 592.207 & 2 & 296.104 & 50.570 & $.000^{\mathrm{b}}$ \\
\hline 1 & Residual & 421.579 & 72 & 5.855 & & \\
\hline & Total & 1013.787 & 74 & & & \\
\hline
\end{tabular}

a. Dependent Variable: Y

b. Predictors: (Constant), X2, X1

Berdasarkan tabel tersebut dapat dilihat bahwa nilai $\mathrm{F}_{\text {hitung }}$ yaitu $50.570>$ dari nilai $\mathrm{F}_{\text {tabel }}$ yaitu 2.73 dan nilai signifikan $0.000<$ dari alpha 0.05 .

Maka keputusan yang diambil $\mathrm{H}_{0}$ ditolak $\mathrm{H}_{1}$ diterima. Dengan diterimanya $\mathrm{H}_{1}$ menunjukkan bahwa variabel bebas yang terdiri dari promosi $\left(\mathrm{X}_{1}\right)$ dan fasilitas $\left(\mathrm{X}_{2}\right)$ mampu menjelaskan keragaman variabel terikat jumlah pengunjung (Y). Dengan demikian variabel promosi dan fasilitas berpengaruh positif dan signifikan terhadap jumlah pengunjung pada Museum Daerah Kabupaten Deli Serdang.

c. Uji Parsial ( Uji t)

Uji parsial (Uji t) bertujuan untuk melihat pengaruh promosi dan fasilitas terhadap jumlah pengunjung pada Museum Daerah Kabupaten Deli Serdang, dengan kriteria:

a. Jika $t_{\text {hitung }}<\mathrm{t}_{\text {tabel }}$, maka $\mathrm{H}_{0}$ diterima, $\mathrm{H}_{1}$ ditolak, artinya secara parsial penelitian ini tidak berpengaruh.

b. Jika $t_{\text {hitung }}>\mathrm{t}_{\text {tabel }}$, maka $\mathrm{H}_{0}$ ditolak, $\mathrm{H}_{1}$ diterima, artinya secara parsial penelitian ini berpengaruh.

Tabel 9. Hasil Uji Parsial ( Uji t)

Coefficients $^{\mathrm{a}}$

\begin{tabular}{|l|l|l|l|l|l|}
\hline Model & \multicolumn{2}{|l|}{$\begin{array}{l}\text { Unstandardized } \\
\text { Coefficients }\end{array}$} & $\begin{array}{l}\text { Standardized } \\
\text { Coefficients }\end{array}$ & \multirow{2}{*}{ Sig. } \\
\cline { 2 - 4 } & B & Std. Error & Beta & & \\
\hline (Constant) & 8.512 & 3.503 & & 2.430 & .018 \\
X1 & .557 & .133 & .527 & 4.189 & .000 \\
X2 & .222 & .102 & .274 & 2.178 & .033 \\
\hline
\end{tabular}

a. Dependent Variable: Y

Berdasarkan tabel tersebut dapat dilihat bahwa:

1. Nilai $\mathrm{t}_{\text {hitung }}$ untuk variabel Promosi $4.189>\mathrm{t}_{\text {tabel }} 1.99$, maka $\mathrm{H}_{0}$ ditolak, $\mathrm{H}_{1}$ diterima, dengan demikian variabel Promosi berpengaruh positif terhadap jumlah pengunjung.

2. Nilai $t_{\text {hitung }}$ untuk variabel Fasilitas $2.178>\mathrm{t}_{\text {tabel }} 1.99$ dan nilai signifikan $0.033<$ dari alpha 0.05 , maka $\mathrm{H}_{0}$ ditolak, $\mathrm{H}_{1}$ diterima, dengan demikian variabel Fasilitas berpengaruh terhadap jumlah pengunjung

\section{Pembahasan}

Hasil pengujian hipotesis pertama menunjukkan bahwa variabel Promosi dan Fasilitas mampu menjelaskan variasi yang terjadi pada jumlah pengunjung di Museum Daerah Kabupaten Deli Serdang, ini dibuktikan dengan nilai koefisien determinasi $\left(\mathrm{R}^{2}\right)$ yang diperoleh sebesar 0.584 atau $58.4 \%$ sedangkan sisanya $41.6 \%$ dipengaruhi oleh variabel lain yang tidak diteliti oleh peneliti dalam penelitian ini.

Hasil pengujian hipotesis kedua menunjukkan bahwa variabel Promosi dan Fasilitas secara simultan berpengaruh positif dan signifikan terhadap jumlah pengunjung pada 
Museum Daerah Kabupaten Deli Serdang, ini dibuktikan dengan $F_{\text {hitung }}$ yaitu $50.570>$ dari nilai $\mathrm{F}_{\text {tabel }}$ yaitu 2.73 dan nilai signifikan $0.000<$ dari alpha 0.05 .

Hasil pengujian hipotesis ketiga menunjukkan bahwa secara parsial promosi berpengaruh pada jumlah pengunjung dan variabel fasilitas berpengaruh pada jumlah pengunjung.

\section{KESIMPULAN}

Berdasarkan hasil penelitian ini dan pembahasan pada bab sebelumnya, maka dapat disimpulkan sebagai berikut:

1. Secara simultan promosi dan fasilitas berpengaruh positif dan signifikan terhadap jumlah pengunjung pada Museum Daerah Kabupaten Deli Serdang.

2. Secara parsial variable promosi berpengaruh positif terhadap jumlah pengunjung, dan variable fasilitas berpengaruh terhadap jumlah pengunjung 


\section{REFERENCES}

Batubara, A., \& Hidayat, R. (2016). Pengaruh Penetapan Harga dan Promosi terhadap Tingkat Penjualan Tiket pada PSA Mihin Lanka Airlines. Jurnal Ilman, 4(1), 3346.

Cece. (2003). Analisis Hubungan Perencanaan Strategi Aliansi PDAM Tirtanadi-PT. Telekominikasi Divre I Terhadap Peningkatan Kualitas Pelayanan Pelanggan PDAM Tirtanadi... Universitas Sumatera Utara.

Dewi, S. P., \& Hidayat, R. (2014). Pengaruh Net Profit Margin dan Return on Assets terhadap Harga Saham pada Perusahaan Otomotif yang terdaftar di Bursa Efek Indonesia. Jurnal Ilman, 1(1), 1-10.

Dinamika, S. G. (2018). Gemstone Fever Hits Jakarta: A Lexical Meaning Analysis.

Dinamika, S. G., \& Sari, W. V. (2015). Applied Error Analysis of Comparative Degree Sentence Construction of Students in STIM Sukma Medan. Asian EFL Journal, 5, $112-119$.

Fathimah, V. (2017). Pengaruh Perkembangan Jumlah Tabungan, Deposito dan Bagi Hasil terhadap Jumlah Pembiayaan yang Diberikan oleh Perbankan Syariah di Sumatera Utara. Jurnal Ilman, 5(1), 41-52.

Hidayat, R. (2009). Penerapan Sistem lnformasi Manajemen sebagai Alat Pelaksanaan Sistem Administrasi Akademik. JURIDIKTI: Jurnal Ilmiah Pendidikan Tinggi, $2(2), 56-59$.

Kotler P, \& KellerK.L. (2012). Marketing Management (14th ed.). New Jersey: Pearson Prestise Hall.

Kriskaritta, N. V. (2013). Pengaruh bauran promosi terhadap keputusan kunjungan konsumen pariwisata. FAKULTAS EKONOMI KA DAN BISNIS UNIVERSITAS DIPONEGORO SEMARANG.

Manap, H. A. (2016). REVOLUSI MANAJEMEN PEMASARAN. Jakarta: Mitra Wacana Media.

Marvidola, T. (2014). PERSEPSI WISATAWAN TENTANG PROMOSI DAN FASILITAS OBJEK WISATA MUSEUM ADITYAWARMAN DI KOTA PADANG. UNIVERSITAS NEGERI PADANG.

Nasution, W. A. (2013). Pengaruh kompensasi dan lingkungan kerja terhadap kepuasan kerja karyawan pada PT. Karya Deli Stelindo Medan. Jurnal Manajemen Bisnis STIE IBBI, 20(2), 1-77.

Ningratri, Y. A. (2017). Analisis Pengaruh Strategi Bauran Pemasaran Jasa (3P) terhadap Keputusan Mahasiswa Memilih STIM Sukma Medan. Riset \& Ejurnal Manajemen Informatika, 3(1), 50-56..

Nuriata. (2014). PAKET WISATA,Penyusunan Produk dan Penghitungan Harga (1st ed.). Bandung: Alfabeta.

Prana, R. R. (2016). Analisis Faktor-faktor yang Mempengaruhi Pendapatan Asli Daerah (PAD) Kota Tebing Tinggi. Jurnal Ilman, 4(1), 74-86. 
Savoy, I. (2015). Pengertian / Definisi Museum dan Fasilitas yang ada di Dalamnya. Retrieved March 15, 2017, from http://arsigraf.blogspot.co.id/2015/11/pengertiandefinisi-museum-dan.html

Sinuhaji, E. (2010). PENERAPAN LAYANAN UNGGUL DALAM PEMASARAN PRODUK BANK. Jurnal Mediasi, 2(1).

Sugiyono. (2012). Metode Penelitian Bisnis (Pendekatan Kuantitatif, Kualitatif, dan $R \& D)$. Bandung: Alfabeta.

Sugiyono. (2016). STATISTIKA UNTUK PENELITIAN. Bandung: Alfabeta.

Sukendro, H. A. (2012). Pengaruh Citra Merek dan Kualitas Pelayanan terhadap Kepuasan Jama'ah pada Kelompok Bimbingan Ibadah Haji (KBIH) Indosat Medan. Universitas Terbuka.

Supriyanto, \& Hidayat, R. (2010). Rancangan Sistem Informasi Administrasi Akademik berbasis Komputer. JURIDIKTI: Jurnal Ilmiah Pendidikan Tinggi, 3(3), 147-157.

Taufikzk. (2016). Pengertian Wisatawan. Retrieved March 15, 2017, from https://taufikzk.wordpress.com/2016/02/01/pengertian-wisatawan/

Tjiptono, F. (2012). Pemasaran Stategik (2nd ed.). Yogyakarta: Andi Ofset.

Wardayani. (2013). Pengaruh Pengetahuan Dewan Tentang Anggaran, Partisipasi Masyarakat dan Transparansi Kebijakan Publik terhadap Kinerja DPRD dalam Pengawasan Keua. Jurnal BIS-A Politeknik LP3i Medan, 2, 35-45.

Wardayani. (2015). ANALISIS KINERJA KEUANGAN PADA PT. SIAR HARAMAIN INT. WISATA MEDAN. Jurnal Bis-A: Jurnal Bisnis Administrasi, 4(2), 14-24.

Widayati, A. (2012). Bali Sebagai Salah Satu Destinasi Pariwisata Favorite Wisata Jepang. Universitas Indonesia.

Widjanarko, B. (2015). PENGARUH PEMERIAN KOMPENSASI DAN KOMUNIKASI TERHADAP SEMANGAT KERJA KARYAWAN PADA BUMI KARYA TAMA INSURANCE CABANG MEDAN. Jurnal Research Sains, 1(2), $130-152$.

Winata, E. (2015). Pengaruh Pemberian Kompensasi dan Penilaian Prestasi Kerja terhadap Produktivitas kerja Karyawan pada PT. Askrindo cabang Medan. Jurnal Dunia Ilmu, 1(2).

Zebua, M. (2016). Pemasaran Pariwisata: (Menuju Festival Sail Daerah). Yogyakarta: Budi Utama.

Zuhri, \& Pertiwi, L. S. (2016). Airline revenue management under number of no-shows uncertainty. Global Journal of Pure and Applied Mathematics, 12(1), 1003-1012.

Zuhri. (2015). Model Input Output dan Aplikasinya pada Enam Sektor. Jurnal Ilman, $3(1), 16-21$. 